\title{
Perceived morbidity and community burden after a Chikungunya outbreak: the TELECHIK survey, a population-based cohort study
}

\author{
Patrick Gérardin ${ }^{1,2,3^{*}}$, Adrian Fianu', Denis Malvy ${ }^{4}$, Corinne Mussard ${ }^{1}$, Karim Boussaïd ${ }^{1}$, Olivier Rollot ${ }^{1}$,
} Alain Michault ${ }^{5}$, Bernard-Alex Gaüzere ${ }^{6}$, Gérard Bréart ${ }^{3,7}$, François Favier ${ }^{1}$

\begin{abstract}
Background: Persistent disabilities are key manifestations of Chikungunya virus (CHIKV) infection, especially incapacitating polyarthralgia and fatigue. So far, little is known about their impact on health status. The present study aimed at describing the burden of CHIKV prolonged or late-onset symptoms on the self-perceived health of La Réunion islanders.

Methods: At 18 months after an outbreak of Chikungunya virus, we implemented the TELECHIK survey; a retrospective cohort study conducted on a random sample of the representative SEROCHIK population-based survey. A total of 1,094 subjects sampled for CHIKV-specific lgG antibodies in the setting of La Réunion island in the Indian Ocean, between August 2006 and October 2006, were interviewed about current symptoms divided into musculoskeletal/rheumatic, fatigue, cerebral, sensorineural, digestive and dermatological categories.

Results: At the time of interview, $43 \%$ of seropositive (CHIK+) subjects reported musculoskeletal pain (vs 17\% of seronegative (CHIK-) subjects, $P<0.001$ ), $54 \%$ fatigue (vs 46\%, $P=0.04$ ), $75 \%$ cerebral disorders (vs $57 \%, P<0.001$ ), $49 \%$ sensorineural impairments (vs 37\%, $P=0.001$ ), $18 \%$ digestive complaints (vs $15 \%, P=0.21$ ), and $36 \%$ skin involvement (vs 34\%, $P=0.20$ ) on average 2 years after infection (range: 15-34 months). After controlling for confounders such as age, gender, body mass index or major comorbidities in different Poisson regression models, $33 \%$ of joint pains were attributable to $\mathrm{CH} \mid \mathrm{KV}, 10 \%$ of cerebral disorders and $7.5 \%$ of sensorineural impairments, while Chikungunya did not enhance fatigue states, digestive and skin disorders.

Conclusions: On average, 2 years after infection $43 \%$ to $75 \%$ of infected people reported prolonged or late-onset symptoms highly attributable to CHIKV. These manifestations carry a significant burden in the community in the fields of rheumatology, neurology and sensorineural health.
\end{abstract}

\section{Background}

Chikungunya virus (CHIKV) is an enveloped RNA positive-strand alphavirus belonging to the Togaviridae family, transmitted by Aedes mosquitoes [1]. CHIKV is now known to target human epithelial and endothelial cells, fibroblasts and macrophages [2], human muscle satellite cells [3], and to cause a wide range of acute manifestations including fever, arthralgia, myalgia, rash and fatigue $[4,5]$. Furthermore, CHIKV infection often

\footnotetext{
* Correspondence: patrick.gerardin@chr-reunion.fr

${ }^{1}$ Centre for Clinical Investigation-Clinical Epidemiology (CIC-EC) of La

Réunion (INSERM/CHR/URMLR), Saint Pierre, La Réunion, France

Full list of author information is available at the end of the article
}

leads to prolonged joint pain, whose stability or relapses characterize the hallmark symptom of 'Chikungunya rheumatism' [5-7]. The basis of musculoskeletal pain and chronic arthropathy observed after acute CHIKV infection may come from the early escape of CHIKV from blood monocytes [8], allowing its relocation to synovial macrophages, as seen with the Ross River virus (RRV) [9], rather than from autoimmunity. The persistence of CHIKV in such sanctuaries triggers a sustained low-noise $\mathrm{T}$ helper 1 cell (Th1) response leading to chronic inflammation and fibrosis, as shown by recent findings in a non-human primate model [10]. Such a pathway has been previously outlined by a single case

\section{C) Biomed Central}


report and subsequently confirmed by a large case series, both from La Réunion Island infected individuals $[11,12]$.

Beyond these common features, CHIKV infection also exhibits more atypical forms $[13,14]$. These include cerebral disorders resulting from a now well established neurotropism $[15,16]$, ranging from mild disrupted behavior or altered mental status to severe encephalopathy/encephalitis [16-19] and to various sensorineural impairments [20,21]. Concurrently, CHIKV infection is known to account for a broad spectrum of mucocutaneous lesions [22,23]. Interestingly, investigation of the pathogenesis, natural course and clinical impact has so far been neglected.

These prolonged or late-onset symptoms occur either at the acute stage or during convalescence and their clinical picture is neither specific nor consistent between individuals. Whether these manifestations are directly attributable to CHIKV infection or represent the exacerbation or complications of underlying conditions, such as osteoarthritis [7], or account for the mode of entry of a subsequent chronic disease, such as rheumatoid arthritis (RA) or psoriatic rheumatism [24,25], is still unknown. Moreover, their clinical burden for the community has not been researched beyond a small and non-representative matched cohort study [26].

To address these important topics, we designed the TELECHIK survey, a telephonic interview through the framework of the SEROCHIK survey. The goal of the SEROCHIK survey was to clarify the seroprevalence and the risk factors of CHIKV infection within the community of La Réunion in the context of the large-scale epidemic that swept the island in 2005-2006 [27,28]. The current study assesses the self-perceived morbidity by La Réunion islanders but also reveals the public health impact of Chikungunya disease in showing the true areas of the community burden, on average 18 months after the outbreak incident.

\section{Methods}

\section{Study design and population}

Participants were enrolled in a retrospective cohort study, the TELECHIK survey, designed from the framework of the cross-sectional, population-based SEROCHIK survey $[27,28]$. The latter, conducted in La Réunion between 17 August and 20 October 2006 soon after an outbreak of Chikungunya virus (June 2006), involved a representative sample of 2,442 index individuals for whom their medical history in relation to Chikungunya was sought and a specific serological enzyme-linked immunosorbent assay (ELISA) test performed [27].

Exposure to CHIKV was defined as positive for the subjects with positive CHIKV-specific IgG antibodies. Seropositive $(\mathrm{CHIK}+)$ and seronegative (CHIK-) subjects were allocated by classifying the previous exposure item within six strata defined at the time of the SEROCHIK survey as follows: true positive (TP, symptomatic CHIK + ), false negative (FN, asymptomatic $\mathrm{CHIK}+$ ), not knowing positive (NKP, CHIK+ without memories of symptoms and serostatus), true negative (TN, asymptomatic CHIK- negative), false positive (FP, symptomatic CHIK), not knowing negative (NKN, CHIK- without reminiscence of symptoms and serostatus) in order to account for the declaration bias beyond the representativeness of our cohort. Taking into account a feasibility constraint, two subsets of the same size of TP and TN subjects were randomly selected after stratification for age, gender and area of residence, with the aim to control the repartition bias. This allocation was conducted by applying reasoned sampling fractions (TP: 0.7 and TN: 0.46), while FP, NKP, FN, NKN, and fewer at SEROCHIK inclusion, were all systematically selected.

\section{Setting}

La Réunion is a French overseas 'département' of 805,500 inhabitants, located on a volcanic island of $2,511 \mathrm{~km}^{2}$ belonging to the Mascarene archipelago in the southwestern Indian Ocean. In 2005-2006, La Réunion was, for the first time in its history, overwhelmed by a Chikungunya epidemic of unprecedented magnitude. More than 266,000 clinical cases were noted by the public health authorities and nearly 300,000 inhabitants (38.2\%) were considered to have been infected [27]. The main reason for such widespread emergence of CHIKV was a single mutation in the envelope protein gene (E1-A226V) that increased the fit of the virus for its principal vector, Aedes albopictus, the Asian tiger mosquito [29,30]. Furthermore, Ae albopictus, was known to exhibit an unusual adaptive property to the human host (so-called anthropization) in La Réunion for a period [31], which was later highlighted by the recent entomological surveys [32].

\section{Data collection}

Participants were interviewed by telephone between November 2007 and May 2008. A short questionnaire was administered by one blinded investigator (CM) to ensure the best possible reproducibility. It was composed of closed questions addressing the most currently reported symptoms. The latter accounted for musculoskeletal pain, headache, digestive disorders, sleeping disorders, memory troubles, attention difficulties, mood disturbance, depression, blurred vision, hearing difficulties, skin lesions, and alopecia.

Body mass index (BMI) was calculated as weight $(\mathrm{kg})$ divided by the square of height $\left(\mathrm{m}^{2}\right)$. Weight and height, as all the relevant comorbidities, were reported from the SEROCHIK survey. Parents or legal guardians were interviewed for persons aged under 15 years. 


\section{Sample size determination and statistical analysis}

The sample size was determined to enable the detection of a minimum $10 \%$ difference between infected $(\mathrm{CHIK}+)$ TP and uninfected (CHIK-) healthy TN subjects in musculoskeletal pain frequency, assuming a one-sided type I error of $5 \%$ and a power of $90 \%$. The more conservative scenario, depicting a baseline incidence of musculoskeletal pain between $40 \%$ and $50 \%$ in the adult TN population, as suggested by those observed in the general UK population [33], and between 50\% and $60 \%$ in the TP adult population (CHIK+ patients), required 560 TP, 560 TN, all the FP, NKP, FN, and NKN subjects, assuming a loss level of $33 \%$, due to incomplete data plus non-responders.

Assessment of current symptoms according to explanatory variables was conducted by bivariate analysis. Proportions were compared using corrected design-based $\chi^{2}$ tests and means using the adjusted Wald test as appropriate. Symptoms were categorized as musculoskeletal/rheumatic, fatigue, light cerebral (headache, and/or sleep disorders, memory troubles, attention difficulties, mood disturbance, depression), sensorineural (blurred vision, hearing difficulties), digestive (digestive disorders) and dermatological (skin lesions, alopecia). Crude prevalence ratios (cPR) and 95\% confidence intervals (95\% CIs) of CHIKV infection were generated using Poisson regression models for each symptom and category. The crude etiology fraction (EF) and 95\% CI of CHIKV infection was calculated for each category linked to Chikungunya to assess the accountability of CHIKV in the genesis of an area of symptoms, as follows: EF $(\%)=\left(\pi_{1}-\pi_{0} / \pi_{1}\right)$ $\times 100$, with $\pi_{1}$ the prevalence of the symptom among $\mathrm{CHIK}+$ subjects and $\pi_{0:}$ the prevalence of the symptom among CHIK- subjects. Adjusted prevalence ratios (aPR) and 95\% CIs for Chikungunya were calculated in Poisson regression models controlling major confounders such as age, gender, BMI, and comorbidities. The population attributable risk (PAR) of CHIKV infection was calculated to assess the community burden of Chikungunya within the perceived morbidity on a population basis. To account for a possible subjectivity bias inherent of FP, NKP, FN, and NKN subjects, we did a sensitivity analysis in the sample restricted to TP and TN. To determine whether the knowledge of previous exposure may affect self-perceived morbidity later on follow-up, we also compared the declaration of each symptoms within FP and FN subsets, assuming that the subjectivity inherent to FP be expressed steadily over time. Finally, we tested the hypothesis that for CHIK+ TP subjects, a previous declaration of intense symptoms (defined as reports of fever plus arthralgia and/or myalgia at the onset of infection) was associated with a more frequent symptoms declaration on follow-up, assuming that subjectivity would not change the expected gradient of declarations from $\mathrm{TN}$ to intense $\mathrm{TP}(\mathrm{TN}<$ mild $\mathrm{TP}<$ intense $\mathrm{TP})$. For all theses analyses, we took special care to verify that the timing of questioning was similar across the groups, and the multiple stage complex sampling procedure was taken into account. Statistical significance was set at $P=0.05$. EpiData software (v.3.1; EpiData, Copenhagen, Denmark) was used for data entry and Stata (v.10.0; StataCorp, College Station, TX, USA) for the analysis.

\section{Ethical considerations}

During the SEROCHIK survey, which had previously received ethical approval from the ethical committee for studies with human subjects (CPP) of Bordeaux and the National Commission for Informatics and Liberty (CNIL) [27], the participants had been informed that they might be called back for ancillary research [26]. During the telephone interview, the objectives of the TELECHIK survey were presented and oral consent to participate was obtained.

\section{Results}

Among the 1,542 individuals selected, 5 had died since the SEROCHIK survey (no death certificate mentioned Chikungunya as the leading cause for death; source: cepiDC, INSERM, France), 359 had missing contact details, 20 refused to answer the questionnaire and 54 were excluded from the analysis because of incomplete data or mismatched responders (different from the index person, parents, legal guardian); thus, 1,094 index individuals were retained for analysis (Figure 1).

The mean age of the participants was 36 years (range: 1 month to 93 years); $39 \%$ of subjects were aged less than 30 years, $48 \%$ were 30 to 59 years and $13 \%$ were 60 years or older. The male to female ratio was 0.74 . The distribution of the area of residence was representative of the one observed in the community (Table 1). More females were participants compared to non-participants (59.0\% vs $52.7 \%, P=0.02$ ), while age and residential area did not differ.

Overall, following a mean time of 16 months from the SEROCHIK survey (range: 13-20 months, on average 15.93 months for CHIK+ vs 15.97 months for CHIK-, $P=0.60), 80.9 \%$ of the 1,094 participants interviewed for the TELECHIK survey reported 1 or more symptoms. The time elapsed between infection and telephone interview in $\mathrm{CHIK}+$ subjects is given in Additional file 1.

Among infected individuals, the 413 TP subjects (median time between infection and interview: 23.7 months, $\mathrm{Q}_{1}-\mathrm{Q}_{3}$ : 21.9-24.9 months, mode: 25 months, range: 15-34 months) did not differ from $67 \mathrm{FN}$ and 32 NKP subjects on age, gender, BMI and major comorbidities, which allowed the consolidation of the 3 groups into 1 of 512 $\mathrm{CHIK}+$ subjects. Similarly, among uninfected peers, even though 396 TN subjects were younger than $81 \mathrm{FP}$ or 


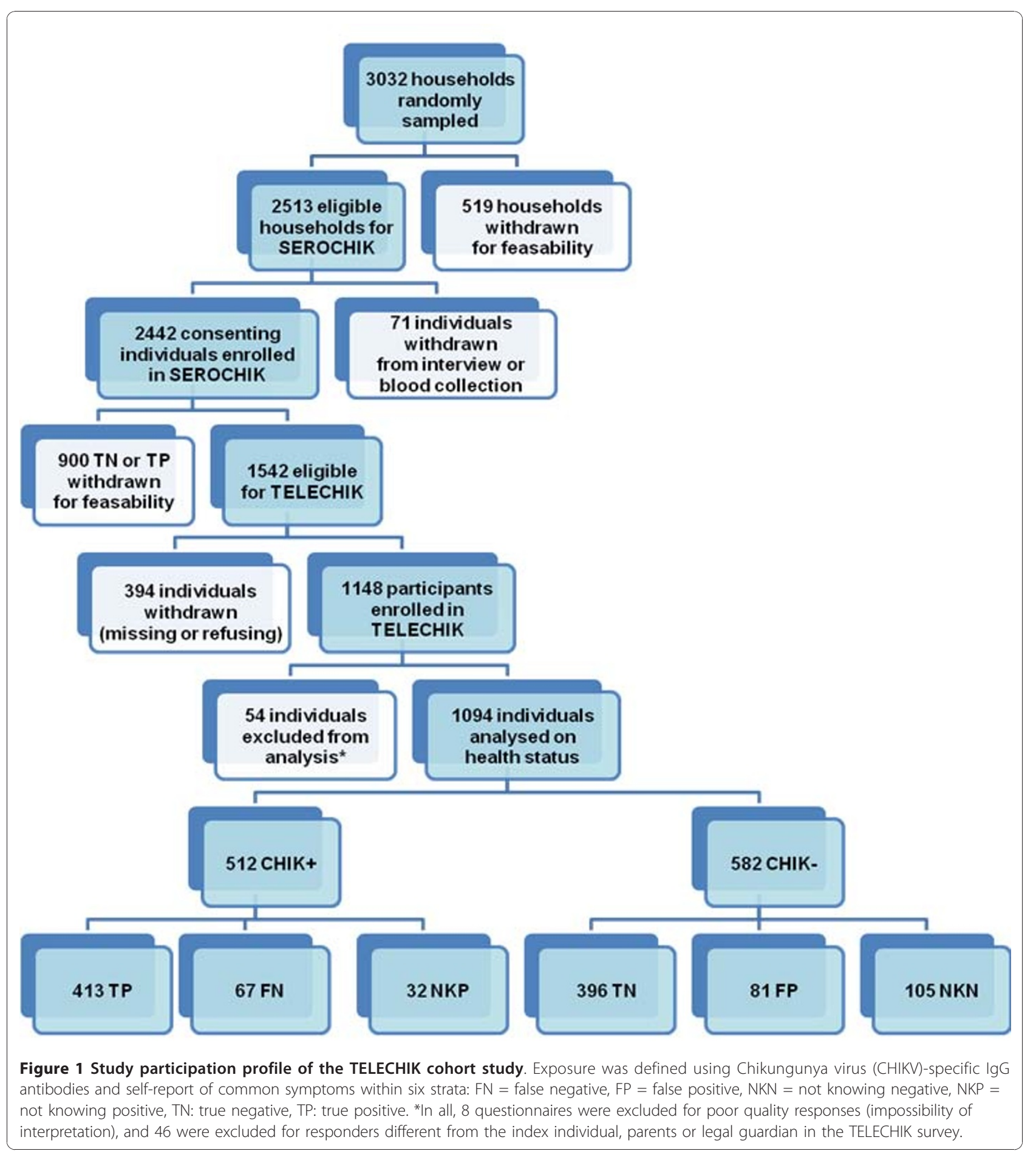

105 NKN subjects, and FP subjects more likely to declare several comorbidities, TN, FP, and NKN subjects were also regrouped into 1 group (CHIK-) to simplify the comparisons.

The crude PRs and 95\% CIs for CHIKV infection for the current self-reported symptoms and categories of symptoms are shown in Table 2 . CHIK+ subjects were more likely than CHIK- peers to complain of musculoskeletal pain (43\% vs $17 \%$, Crude PR: 2.5 , 95\% CI 1.9 to 3.1) with a high proportion attributable to CHIKV infection (EF: $60.0 \%$, 95\% CI $51.8 \%$ to $68.2 \%$ ). CHIK+ subjects also more frequently reported fatigue, light cerebral disorders, and sensorineural impairment than their CHIK- peers. The EF of CHIKV infection was $13.5 \%$ 
Table 1 Characteristics of the 1,094 subjects analyzed for current health status at follow-up TELECHIK survey, November 2007 to May 2008, and of La Réunion Island population

\begin{tabular}{lll}
\hline Characteristics, $\mathbf{n}(\%)$ & TELECHIK & INSEE $^{\mathbf{a}}$ \\
\hline Gender: & $645(57.4)$ & $414,855(51.5)^{\mathrm{b}}$ \\
\hline Women & $449(42.6)$ & $390,645(48.5)$ \\
\hline Men & & \\
\hline Age, years: & $214(27.6)$ & $281,680(35.0)^{\mathrm{b}}$ \\
\hline$<20$ & $124(11.8)$ & $106,277(13.2)$ \\
\hline 20 to 29 & $159(16.3)$ & $118,412(14.7)$ \\
\hline 30 to 39 & $180(17.6)$ & $123,616(15.3)$ \\
\hline 40 to 49 & $187(14.2)$ & $84,122(10.4)$ \\
\hline 50 to 59 & $133(7.7)$ & $49,397(6.1)$ \\
\hline 60 to 69 & $97(4.8)$ & $41,996(5.2)$ \\
\hline Residential area: ${ }^{c}$ & & \\
\hline North & $249(22.8)$ & $190,625(24.4)^{d}$ \\
\hline East & $167(15.3)$ & $114,278(14.6)$ \\
\hline South & $403(36.8)$ & $277,602(35.5)$ \\
\hline West & $275(25.1)$ & $199,457(25.5)$ \\
\hline
\end{tabular}

${ }^{a}$ Institut National de la Statistique et des Etudes Economiques; ${ }^{b} 2008$ census; 'La Réunion Island is divided into four administrative microregions: North, East, South, and West; ${ }^{d} 2006$ census.

(95\% CI $3.2 \%$ to $25.8 \%$ ) for fatigue, $24.2 \%$ (95\% CI $17.7 \%$ to $30.8 \%$ ) for light cerebral disorders and $23.8 \%$ (95\% CI 13.3 to $34.3 \%$ ) for sensorineural impairment.

Digestive and skin disorders (including alopecia) were not associated with Chikungunya infection. Among the light cerebral disorders, the most closely linked to CHIKV infection were attention difficulties (EF: 46.3\%, 95\% CI $35.7 \%$ to $57.0 \%$ ), memory trouble (EF: $39.9 \%$, 95\% CI $29.5 \%$ to $50.2 \%$ ), mood disturbance (EF: $38.3 \%$, 95\% CI $27.0 \%$ to $49.5 \%$ ) and depression (EF: $45.6 \%, 95 \%$ CI $26.8 \%$ to $64.4 \%$ ), whereas the association with headache (EF: $22.6 \%, 95 \%$ CI $5.7 \%$ to $39.5 \%$ ) and sleep disorders (EF: $22.9 \%$, 95\% CI $8.0 \%$ to $37.8 \%$ ) was slight. Among sensorineural impairments, Chikungunya infection affected vision (blurred vision, EF: $28.2 \%$, 95\% CI $16.7 \%$ to $39.7 \%$ ) more than hearing (hearing difficulties, EF: $26.7 \%$, 95\% CI $6.2 \%$ to $47.3 \%)$. Consistently, the sensitivity analysis restricted to TP and TN (Additional file 2) depicted the same figures with stronger links, which argued for a causative role of CHIKV in the pathogenesis of symptoms (this time including hearing loss, $P=0.016)$, and indirectly for subjectivity in FP, NKP, FN, and NKN subsets. Against all odds, the FP subjects tended to declare almost every symptom more frequently than the FN subjects on follow-up, which argued for influence of subjectivity rather than knowledge of exposure in self-perceived morbidity at a distance. As expected, the TP subjects with the more intense symptoms at onset of infection complained slightly more frequently on follow-up than mild TP subjects, and far more than TN subjects, confirming the link between intense inaugural symptoms and late manifestations, as the minor role of subjectivity in $\mathrm{CHIK}+$ subjects.

The adjusted PRs and 95\% CIs inherent of CHIKV infection and major confounders for determining

Table 2 Crude weighted rates and prevalence ratios of self-reported symptoms/CHIKV status, TELECHIK survey, La Réunion Island population, November 2007 to May 2008

\begin{tabular}{|c|c|c|c|c|c|}
\hline Symptoms (\%) & Seronegative (CHIK-), \% & Seropositive (CHIK+), \% & Crude prevalence ratio & $95 \% \mathrm{Cl}$ & $P$ value \\
\hline Musculoskeletal pain & 17.1 & 42.8 & 2.5 & 1.9 to 3.1 & $<0.001$ \\
\hline Fatigue & 46.4 & 53.6 & 1.1 & 1.0 to 1.3 & 0.04 \\
\hline Light cerebral disorders & 57.0 & 75.3 & 1.3 & 1.1 to 1.5 & $<0.001$ \\
\hline Headache & 20.0 & 25.9 & 1.3 & 1.0 to 1.7 & 0.05 \\
\hline Sleep disorders & 24.1 & 31.2 & 1.3 & 1.0 to 1.7 & 0.02 \\
\hline Memory troubles & 25.4 & 42.2 & 1.7 & 1.3 to 2.0 & $<0.001$ \\
\hline Attention difficulties & 19.9 & 37.1 & 1.9 & 1.4 to 2.3 & $<0.001$ \\
\hline Mood disturbance & 23.7 & 38.4 & 1.6 & 1.3 to 2.0 & $<0.001$ \\
\hline Depression & 8.0 & 14.7 & 1.8 & 1.2 to 2.7 & 0.002 \\
\hline Sensorineural disorders & 37.2 & 48.8 & 1.4 & 1.1 to 1.5 & 0.001 \\
\hline Blurred vision & 30.2 & 42.0 & 1.4 & 1.1 to 1.7 & $<0.001$ \\
\hline Hearing difficulties & 13.0 & 17.8 & 1.4 & 0.9 to 1.9 & 0.05 \\
\hline Digestive disorders & 15.0 & 18.3 & 1.2 & 0.8 to 1.7 & 0.21 \\
\hline Dermatological disorders & 34.2 & 36.1 & 1.2 & 0.8 to 1.7 & 0.205 \\
\hline Skin lesions & 17.2 & 19.9 & 1.2 & 0.8 to 1.5 & 0.33 \\
\hline Alopecia & 21.4 & 21.9 & 1.0 & 0.7 to 1.3 & 0.835 \\
\hline
\end{tabular}

The weighted rates of the symptoms are expressed as percentages. Chikungunya status is defined by specific anti-CHIKV IgG antibodies. 
Table 3 Adjusted prevalence ratios for the determinants of self-reported rheumatic symptoms, TELECHIK survey, La Réunion Island population, November 2007 to May 2008

\begin{tabular}{|c|c|c|c|}
\hline Determinants & Adjusted prevalence ratio & $95 \% \mathrm{Cl}$ & $P$ value \\
\hline Chikungunya: & & & $<0.001$ \\
\hline No & 1 & & \\
\hline Yes & 2.1 & 1.7 to 2.7 & \\
\hline Gender: & & & 0.08 \\
\hline Male & 1 & & \\
\hline Female & 1.2 & 0.9 to 1.5 & \\
\hline Age, years: & & & $<0.001$ \\
\hline$<20$ & 1 & & \\
\hline 20 to 29 & 1.4 & 0.7 to 2.5 & \\
\hline 30 to 39 & 1.8 & 1.1 to 3.0 & \\
\hline 40 to 49 & 2.7 & 1.7 to 4.2 & \\
\hline 50 to 59 & 3.3 & 2.1 to 5.2 & \\
\hline 60 to 69 & 3.9 & 2.5 to 6.1 & \\
\hline$\geq 70$ & 3.5 & 2.2 to 5.6 & \\
\hline $\begin{array}{l}\text { Body mass index, } \\
\mathrm{kg} / \mathrm{m}^{2} \text { : }\end{array}$ & & & 0.001 \\
\hline$<25$ & 1 & & \\
\hline $25-29.9$ & 1.5 & 1.2 to 1.8 & \\
\hline$\geq 30$ & 1.3 & 0.9 to 1.7 & \\
\hline Comorbidity: $^{a}$ & & & 0.11 \\
\hline None & 1 & & \\
\hline Osteoarthritis & 1.4 & 1.0 to 2.0 & \\
\hline Other $^{a}$ & 1.2 & 0.9 to 1.5 & \\
\hline
\end{tabular}

${ }^{a}$ Diabetes mellitus, hypertension, ischemic heart disease, asthma, chronic obstructive pulmonary disease, renal failure, cancer.

musculoskeletal/rheumatic pain, light cerebral disorders, and sensorineural impairment are shown in Tables 3, 4, 5,6 .

When adjusting for major confounders, on average 24 months (range: 15-34 months) after the acute stage of the infection CHIK+ subjects were twice as likely to report musculoskeletal pain (aPR: 2.1, 95\% CI 1.7 to 2.7) than their CHIK- counterparts (Table 3). Furthermore, they complained more easily of light cerebral disorders (aPR: 1.3, 95\% CI 1.2 to 1.4) (Table 5). Similarly, they were also slightly associated with sensorineural impairment (aPR: 1.2, 95\% CI 1.0 to 1.4) (Table 6). Accordingly, the same models applied to TP and TN subjects (Additional files 3, 4, 5) drew similar conclusions favoring the role of CHIKV, except those dedicated to fatigue. Fatigue was not enhanced in $\mathrm{CHIK}+$ subjects compared with CHIK- peers (aPR: $1.1,95 \%$ CI 0.9 to 1.3) when considering the whole sample (Table 4), whereas it was linked to infection (aPR: $1.2,95 \%$ CI 1.0 to 1.4, $P=0.025$ ) in TP and TN subjects (Additional file 6).
Table 4 Adjusted prevalence ratios for the determinants of fatigue, TELECHIK survey, La Réunion Island population, November 2007 to May 2008

\begin{tabular}{|c|c|c|c|}
\hline Determinants & Adjusted prevalence ratio & $95 \% \mathrm{Cl}$ & $P$ value \\
\hline Chikungunya: & & & 0.11 \\
\hline No & 1 & & \\
\hline Yes & 1.1 & 0.9 to 1.3 & \\
\hline Gender: & & & $<0.001$ \\
\hline Male & 1 & & \\
\hline Female & 1.4 & 1.1 to 1.6 & \\
\hline Age, years: & & & 0.003 \\
\hline$<20$ & 1 & & \\
\hline 20 to 29 & 1.7 & 1.2 to 2.2 & \\
\hline 30 to 39 & 1.5 & 1.1 to 2.0 & \\
\hline 40 to 49 & 1.5 & 1.1 to 2.0 & \\
\hline 50 to 59 & 1.5 & 1.1 to 2.0 & \\
\hline 60 to 69 & 1.4 & 1.0 to 1.8 & \\
\hline$\geq 70$ & 1.7 & 1.2 to 2.3 & \\
\hline Comorbidity: ${ }^{a}$ & & & 0.006 \\
\hline None & 1 & & \\
\hline 1 & 1.2 & 1.0 to 1.5 & \\
\hline 2 & 1.1 & 0.8 to 1.4 & \\
\hline$\geq 3$ & 1.5 & 1.2 to 1.8 & \\
\hline
\end{tabular}

${ }^{a}$ Osteoarthritis, diabetes mellitus, hypertension, ischemic heart disease, asthma, chronic obstructive pulmonary disease, renal failure, cancer.

Importantly, the PARs for Chikungunya to explain musculoskeletal pain, light cerebral disorders and sensorineural impairment, as expressed by the community, were respectively $33.6 \%, 10.4 \%$ and $7.5 \%$. In other words, if Chikungunya had been fully preventable, participants should have reported two-thirds of the musculoskeletal pains, $89.6 \%$ of the light cerebral disorders and $92.5 \%$ of the sensorineural impairments declared in the TELECHIK survey.

\section{Discussion}

Here, we report a large follow-up study dealing with the community burden of Chikungunya long-term manifestations, experienced within the La Réunion population after the 2005-2006 Chikungunya virus outbreak $[6,7,12]$. One of the major findings of our populationbased survey is that self-perceived morbidity, described through several subjective symptoms and categories of manifestations (musculoskeletal pain, fatigue, light cerebral disorders, sensorineural impairment, digestive and skin disorders), on average 18 months after the outbreak, is still largely attributed to Chikungunya. Thus, among previously exposed individuals (CHIK+ subjects), CHIKV would be involved in $60 \%$ of musculoskeletal pains (characterized indistinctively as joint, bone or muscle aches), approximately a quarter of cerebral 
Table 5 Adjusted prevalence ratios for the determinants of light cerebral disorders, TELECHIK survey, La Réunion Island population, November 2007 to May 2008

\begin{tabular}{|c|c|c|c|}
\hline Determinants & Adjusted prevalence ratio & $95 \% \mathrm{Cl}$ & $P$ value \\
\hline Chikungunya: & & & $<0.001$ \\
\hline No & 1 & & \\
\hline Yes & 1.3 & 1.1 to 1.4 & \\
\hline Gender: & & & 0.002 \\
\hline Male & 1 & & \\
\hline Female & 1.2 & 1.0 to 1.3 & \\
\hline Age, years: & & & 0.83 \\
\hline$<20$ & 1 & & \\
\hline 20 to 29 & 1.1 & 0.8 to 1.3 & \\
\hline 30 to 39 & 0.9 & 0.8 to 1.2 & \\
\hline 40 to 49 & 1.0 & 0.8 to 1.2 & \\
\hline 50 to 59 & 1.1 & 0.9 to 1.3 & \\
\hline 60 to 69 & 1.0 & 0.8 to 1.2 & \\
\hline$\geq 70$ & 0.9 & 0.7 to 1.2 & \\
\hline Comorbidity: $^{\text {a }}$ & & & 0.04 \\
\hline None & 1 & & \\
\hline 1 & 1.1 & 0.9 to 1.3 & \\
\hline 2 & 1.2 & 1.0 to 1.4 & \\
\hline$\geq 3$ & 1.2 & 0.9 to 1.6 & \\
\hline
\end{tabular}

a Osteoarthritis, diabetes mellitus, hypertension, ischemic heart disease, asthma, chronic obstructive pulmonary disease, renal failure, cancer.

disorders and of sensorineural impairments, and 13\% of fatigue states. Moreover, at the general population level, after controlling major confounders, Chikungunya could explain a third of rheumatic symptoms, $10 \%$ of neurological and $7.5 \%$ of sensorineural complaints. These features highlight a previously misrecognized impact of CHIKV infection in the fields of rheumatology, neurology and sensorineural health.

To the best of our knowledge, beyond a smaller nonrepresentative matched cohort study [26], no comparative study to date had attempted to establish the responsibility of Chikungunya for the persistence (or the delayed onset) of non-specific common symptoms, nor its public health impact. To address these questions we designed the TELECHIK study, a comparison set beyond the framework of the population-based SEROCHIK survey that allowed the selection of a random sample of the La Réunion island community $[27,28]$. Moreover to enable a random homogeneous allocation of subjectivity determinants of the symptoms reported, we also adjusted for major confounders of health status in order to assess the proper role of CHIKV infection in perceived morbidity. These restrictions, both in design and analysis, were necessary to make a causal relationship plausible between CHIKV and its related manifestations. Indeed, they are now recognized as
Table 6 Adjusted prevalence ratios for the determinants of sensorineural impairment, TELECHIK survey, La Réunion Island population, November 2007 to May 2008

\begin{tabular}{|c|c|c|c|}
\hline Determinants & Adjusted prevalence ratio & $95 \% \mathrm{Cl}$ & $P$ value \\
\hline Chikungunya: & & & 0.02 \\
\hline No & 1 & & \\
\hline Yes & 1.2 & 1.0 to 1.4 & \\
\hline Gender: & & & 0.36 \\
\hline Male & 1 & & \\
\hline Female & 1.1 & 0.9 to 1.3 & \\
\hline Age, years: & & & $<0.001$ \\
\hline$<20$ & 1 & & \\
\hline 20 to 29 & 1.7 & 1.0 to 2.5 & \\
\hline 30 to 39 & 1.4 & 0.9 to 2.1 & \\
\hline 40 to 49 & 2.6 & 1.9 to 3.6 & \\
\hline 50 to 59 & 2.7 & 1.9 to 3.7 & \\
\hline 60 to 69 & 2.7 & 1.9 to 3.8 & \\
\hline$\geq 70$ & 2.6 & 1.7 to 3.7 & \\
\hline Comorbidity: & & & 0.20 \\
\hline None & 1 & & \\
\hline 1 & 1.1 & 0.9 to 1.3 & \\
\hline 2 & 1.2 & 0.9 to 1.5 & \\
\hline$\geq 3$ & 1.3 & 0.9 to 1.6 & \\
\hline
\end{tabular}

${ }^{a}$ Osteoarthritis, diabetes mellitus, hypertension, ischemic heart disease, asthma, chronic obstructive pulmonary disease, renal failure, cancer.

an indisputable prerequisite to improve the standard of proof of observational studies [34].

The reality of 'Chikungunya rheumatism' was suggested formerly in a few case report series [35-37]. It has also been supported in recent years by several observational studies [4-7,38,39], whose design should not have definitely attributed such non-specific symptoms to CHIKV. For instance, in Transvaal, South Africa, 15\% of patients complained of persistent arthralgia 20 months after acute infection [35], while $12 \%$ reported recurrent relapsing joint pain, stiffness or swelling 3 to 5 years after Chikungunya onset [36]. Nonetheless, these assessments were not conducted with any formal evaluation of the community burden of such symptoms. In contrast, cases imported to France from La Réunion exhibited a heavier burden with rheumatic manifestations of at least $48 \%$ 6 months to 2 years after the acute infection $[38,39]$. Of note, among La Réunion islanders, the persistence of rheumatic pain was perceived to be at a similarly alarming level, with $57 \%$ of CHIK+ subjects from a nonrepresentative sample of the population experiencing permanent or recurrent polyarthralgia after a course of 15 months [7]. Consistently, the figure rose to $64 \%$ in hospitalized $\mathrm{CHIK}+$ patients at 18 months post infection [6]. However, in all these studies, the causality between 
subjective rheumatic symptoms and CHIKV infection was questionable, either due to participation and selection biases, to absence of standardization in symptom elicitation, to lack of clinical review, and to the absence of an uninfected control group to assess symptom rates at baseline.

Infections with other 'arthritogenic' alphaviruses such as RRV or Sindbis-related (Pogosta) virus were associated with same magnitude of incidence (50\% to $60 \%$ ) of persisting arthralgia 6 months to 3 years after acute infection [40-43]. Interestingly, half of the cohort of RRV patients exhibited signs over time of chronic rheumatic disease [44]. Similarly, Borgherini et al. reported that $44 \%$ of Réunionese patients declaring prolonged Chikungunya arthritis had a previous history of joint pain [6]. Accordingly, Sissoko et al. identified the presence of underlying osteoarthritis (OA) comorbidity as a significant risk factor for non-recovery [7]. This is why the possibility of overlap between a rheumatic pre-existing underlying condition and an authentic Chikungunya-specific arthralgia led the more skeptical contributors to think that prolonged signs of 'arthritogenic' alphaviruses could represent the mode of revelation of chronic rheumatic diseases, such as RA or psoriatic rheumatism $[6,23,24,42,43]$.

Our study has shown that among CHIKV infected individuals, $60 \%$ of polyarthralgia could be attributed to CHIKV. The understanding of the musculoskeletal symptoms of Chikungunya has taken a significant step forward with the recent development of a non-human primate model [10]. These data confirm the central place of the macrophage as the main target cell for CHIKV dissemination and persistence within the organism, as well as being the cornerstone for CHIKV rheumatic pathophysiology $[8,11,12]$. Thus, similarly to RRV or RA [9], an inadequate host innate immune (Th1) response to CHIKV could damage cartilage and be the source of OA degenerative lesions [45]. With regard to the potential community burden of Chikungunyaspecific rheumatism, efforts should focus on the control of Chikungunya joint damage with pre-existing or newly developed anti-inflammatory drugs $[9,24,46]$. For these reasons, further research including randomized clinical trials are required to better understand the mechanisms of CHIKV pathophysiology and promote the prevention of the progression of $\mathrm{OA}$ in areas affected by this 'arthritogenic' virus.

The fact Chikungunya is responsible for so many issues, involved in $13.5 \%$ of fatigue states and in $24.2 \%$ of light cerebral disorders, is not surprising. On the one hand, CHIKV neurotropism is now well documented through various observations at all ages of life [15-19]. Moreover, there is a growing body of evidence for the presence of neuropathic pain in non-responsive CHIKV patients associated with a more aggressive clinical picture and more challenging treatment, which can impair quality of life and even lead to depression [47]. On the other hand, some evidence supports the putative role of the interferon family, and more widely of Th1 cytokines in primary and drug-induced sickness behavior syndromes [48]. Interestingly, the two conditions include tiredness and mood disturbance, both previously related to RRV through the postinfective fatigue syndrome $[49,50]$. Indeed, Th1 cytokines are known to preferentially target neurocircuits relevant to psychomotor activity (for example, basal ganglia) [51]. Whether fatigue and light cerebral disorders in the context of CHIKV disease could share a common neuropathogenesis involving the innate immune system with RRV and other alphaviruses [48], or represent the harmful consequences on psychomotor activity of a long-lasting disease, deserves further research. Nonetheless, there is undoubtedly potential for a significant community burden of CHIKV neurotropism that can no longer be ignored.

Little attention was paid to sensorineural impairment before the recent Chikungunya epidemic. Thus, no observational study has yet focused on ophthalmic and hearing involvements beyond the few case series reported from the Indian subcontinent [20,21]. Our data demonstrate clearly that sensorineural health can be affected during large-scale CHIKV outbreaks, through various complaints such as hearing difficulties and blurred vision, independently of other conditions such as senescence and diabetes mellitus. The basis of these sensorial symptoms is still poorly understood and might depict another facet of CHIKV neurotropism rather than a direct targeting of sensory cells per se.

Taken together, with regard to the other aspects of severe Chikungunya disease over the epidemic, such as maternal-fetal transmission [16], myocarditis, GuillainBarré syndrome $[18,19]$ or other atypical forms with increased background mortality $[13,14]$, the toll of longterm disabilities reported herein supports enhanced virulence of the E1-A226V strain compared to other CHIKV strains involved in previous Asian outbreaks [52], which argues definitively for revisiting Chikungunya as a benign non-fatal illness.

Our study has some strengths and limitations. The investigator was blinded to the serological status of the participants to limit the propensity of classification bias (overestimation of symptoms among CHIK+ subjects). Though participants were interviewed long after the onset of the disease, only ongoing symptoms were considered to minimize recall bias. In contrast with previous studies, a control group was used for comparison and subjects were randomly selected through a populationbased representative cohort [27]. Thus, there was no substantial participation bias favoring patients with severe illness unlike previous hospital-based studies (non- 
representative of the baseline of $\mathrm{CHIK}+$ patients) [26]. The diagnostic accuracy was definitely efficient, as shown by low proportions of asymptomatic cases and false positives $[26,27]$. Finally, we applied population weights to account for the case-mix representativeness and minimize the imbalance produced by selecting more women and older participants. However, patients were not examined physically by clinicians either to rule out differential diagnoses or to assess and confirm the complaints. Moreover, health perceptions may have been disturbed after such a public health catastrophe [53]. These reasons may have skewed the estimation of some of the subjective symptoms assessed in this survey of perceived morbidity. This said, the role of subjectivity could be considered as negligible in this study except for fatigue, as shown by the sensitivity analysis restricted to true positives and true negatives. It is also unlikely that subjectivity or the knowledge of exposure changed the overall meaning of our findings owing to the small proportions of false positives and false negatives in the community [27], and of participants not knowing their serostatus enrolled in the TELECHIK survey. Nevertheless, it is important to emphasize that the disease burden in terms of common manifestations may be overstated by subjectivity and previous knowledge of exposure, especially for an emerging arboviral infection when it is associated with illnessspecific catastrophic thinking [54]. Although this phenomenon seems to us to be relatively marginal, it cannot be ruled out because Chikungunya was ranked third (after AIDS and cancer) on the scale of health risk perceptions shortly after the outbreak (Perrau J et al., personal communication).

\section{Conclusions}

On average, 2 years after onset of infection $43 \%$ to $75 \%$ of $\mathrm{CHIK}+$ patients report prolonged or late-onset symptoms highly attributable to CHIKV. These manifestations carry a significant burden in the community in the fields of rheumatology, neurology and sensorineural health. Our findings lend support to clinical descriptions, pathophysiology, and perception of Chikungunya disease and give a valuable insight towards the understanding of the economic impact of this disabling arboviral disease.

\section{Additional material}

Additional file 1: Distribution of the time elapsed between the onset of infection and the TELECHIK survey in seropositive (CHIK+) subjects. The histogram displays the range of the time elapsed between the onset of infection and telephonic interviews in Chikungunya virus (CHIKV) infected subjects.

Additional file 2: Table S1. Crude weighted rates and prevalence ratios of self-reported symptoms/Chikungunya virus (CHIKV) status from the TELECHIK survey, La Réunion Island population, November 2007 to May 2008. The weighted rates of the symptoms are expressed as percentages in parentheses; Chikungunya status is defined by specific antiChikungunya virus (CHIKV) lgG antibodies. TN = true negative (no selfreported Chikungunya disease with no infection confirmed by CHIKVspecific IgG antibodies); TP = true positive (self-reported Chikungunya disease with infection confirmed by CHIKV-specific IgG antibodies).

Additional file 3: Table S2. Adjusted prevalence ratios for the determinants of self-reported rheumatic symptoms, TELECHIK survey, La Réunion Island population, November 2007 to May 2008. *Diabetes mellitus, hypertension, ischemic heart disease, asthma, chronic obstructive pulmonary disease, renal failure, cancer. TN = true negative (no self-reported Chikungunya disease with no infection confirmed by Chikungunya virus (CHIKV)-specific IgG antibodies); TP = true positive (self-reported Chikungunya disease with infection confirmed by CHIKVspecific lgG antibodies).

Additional file 4: Table S3. Adjusted prevalence ratios for the determinants of light cerebral disorders, TELECHIK survey, La Réunion Island population, November 2007 to May 2008. * Osteoarthritis, diabetes mellitus, hypertension, ischemic heart disease, asthma, chronic obstructive pulmonary disease, renal failure, cancer. TN = true negative (no self-reported Chikungunya disease with no infection confirmed by Chikungunya virus (CHIKV)-specific lgG antibodies); TP = true positive (self-reported Chikungunya disease with infection confirmed by CHIKVspecific lgG antibodies).

Additional file 5: Table S4. Adjusted prevalence ratios for the determinants of sensorineural impairment, TELECHIK survey, La Réunion Island population, November 2007 to May 2008. * Osteoarthritis, diabetes mellitus, hypertension, ischemic heart disease, asthma, chronic obstructive pulmonary disease, renal failure, cancer. TN = true negative (no self-reported Chikungunya disease with no infection confirmed by Chikungunya virus (CHIKV)-specific lgG antibodies); TP = true positive (self-reported Chikungunya disease with infection confirmed by CHIKVspecific lgG antibodies).

Additional file 6: Table S5. Adjusted prevalence ratios for the determinants of fatigue, TELECHIK survey, La Réunion Island population, November 2007 to May 2008. *Osteoarthritis, diabetes mellitus, hypertension, ischemic heart disease, asthma, chronic obstructive pulmonary disease, renal failure, cancer. $\mathrm{TN}=$ true negative (no selfreported Chikungunya disease with no infection confirmed by Chikungunya virus (CHIKV)-specific IgG antibodies); TP = true positive (self-reported Chikungunya disease with infection confirmed by CHIKVspecific lgG antibodies).

\section{Acknowledgements}

We are indebted to the field workers of the SEROCHIK survey, the staff and technicians of the Centre d'Investigation Clinique - Épidémiologie Clinique of La Réunion who collected the sera samples, those of Groupe Hospitalier Sud - Réunion and Institut Pasteur laboratories who analyzed the sera. We thank Joelle Perrau for preparing the database of the SEROCHIK survey. We also thank Doctor Daouda Sissoko and Professor Antoine Flahault for helpful discussions and critical reading of the manuscript. We are grateful to Doctor Pierre-Yves Robillard, head of the NICU/PICU, and to Doctor Georges Barau, head of the 'Pôle Femmes-Mères-Enfants', at the CHR Sud-Réunion, for giving us time to conduct this work. This study was funded by the Institut National de Santé Et de la Recherche Médicale

\section{Author details}

${ }^{1}$ Centre for Clinical Investigation-Clinical Epidemiology (CIC-EC) of La Réunion (INSERM/CHR/URMLR), Saint Pierre, La Réunion, France. ${ }^{2}$ Neonatal and Pediatric Intensive Care Unit, Centre Hospitalier Régional (CHR), Saint Pierre, La Réunion, France. ${ }^{3}$ UMR S953, 'Epidemiological Research on Perinatal Health and Women and Children Health' (INSERM/Assistance Publique des Hôpitaux de Paris), Paris, France. ${ }^{4}$ Department of Internal Medicine and Tropical Diseases, Hôpital Saint André, Bordeaux, France. ${ }^{5}$ Microbiology, CHR, Saint Pierre, La Réunion, France. ${ }^{6}$ Polyvalent Intensive Care Unit, CHR, Saint Denis, La Réunion, France. ${ }^{7}$ Public Health Institute, INSERM, Paris, France. 


\section{Authors' contributions}

PG analyzed the data, drafted and reviewed the manuscript; AF helped to design the study, analyzed the data, reviewed the data for consistency and errors and also checked the manuscript; DM, AM, BAG, GB and FF reviewed the manuscript, each in his field of expertise, for consistency and perspective; $C M$ performed telephone interviews, and entered the data; $\mathrm{KB}$ realized the data management; OR helped to analyze the data; AM performed the serology assays during the SEROCHIK survey; FF was the principal investigator of the SEROCHIK and TELECHIK surveys. All authors read and approved the final manuscript.

\section{Competing interests}

The authors declare that they have no competing interests.

Received: 16 August 2010 Accepted: 14 January 2011

Published: 14 January 2011

\section{References}

1. Porterfield JH: Antigenic characteristics and classification of the Togaviridae.Edited by: Schlesinger R. New York, NY: Academic Press; 1980:13-46.

2. Sourisseau M, Schilte C, Casartelli N, Trouillet C, Guivel-Benhassine F, Rudnicka D, Sol-Foulon N, Le Roux K, Prevost MC, Fsihi H, Frenkiel MP, Blanchet F, Afonso PV, Ceccaldi PE, Ozden S, Gessain A, Schuffenecker I, Verhasselt B, Zamborlini A, Saïb A, Rey FA, Arenzana-Seisdedos F, Desprès P, Michault A, Albert ML, Schwartz O: Characterization of remerging Chikungunyavirus. PLoS Pathog 2007, 3:e89.

3. Ozden S, Huerre M, Riviere JP, Coffey LL, Afonso PV, Mouly V, de Monredon J, Roger JC, El Amrani M, Yvin JL, Jaffar MC, Frenkiel MP, Sourisseau M, Schwartz O, Butler-Browne G, Desprès $P$, Gessain A, Ceccaldi PE: Human muscle satellite cells as targets of Chikungunya virus infection. PLoS One 2007, 2:e527.

4. Borgherini G, Poubeau P, Staikowsky F, Lory M, Le Moullec N, Becquart JP, Wengling C, Michault A, Paganin F: Outbreak of chikungunya on Réunion Island: early clinical and laboratory features in 157 adult patients. Clin Infect Dis 2007, 44:1401-1407.

5. Manimunda SP, Vijayachari P, Uppoor R, Sugunan AP, Singh SS, Rai SK Sudeep AB, Muruganandam N, Chaitanya IK, Guruprasad DR: Clinical progression of chikungunya fever during acute and chronic arthritic stages and the changes in joint morphology as revealed by imaging. Trans R Soc Trop Med Hyg 2010, 104:392-399.

6. Borgherini G, Poubeau P, Jossaume A, Gouix A, Cotte L, Michault A, ArvinBerod C, Paganin F: Persistent arthralgia associated with chikungunya virus: a study of 88 adult patients on Réunion island. Clin Infect Dis 2008, 47:469-475.

7. Sissoko D, Malvy D, Ezzedine $K$, Renault $P$, Moscetti F, Ledrans M, Pierre V: Post-epidemic chikungunya disease on Réunion island: course of rheumatic manifestations and associated factors over a 15 month period. PLoS Neglect Trop Dis 2009, 3:e389.

8. Her Z, Malleret B, Chan M, Ong EK, Wong SC, Kwek DJ, Tolou H, Lin RT, Tambyah PA, Rénis L, Ng LF: Active infection of human blood monocyte by Chikungunya virus triggers an innate immune response. I Immunol 2010, 184:5903-5913.

9. Lidbury BA, Rulli NE, Suhrbier A, Smith PN, McColl SR, Cunningham AL, Tarkowski A, van Rooijen N, Fraser RJ, Mahalingam S: Macrophage-derived proinflammatory factors contribute to the development of arthritis and myositis after infection with an arthrogenic alphavirus. J Infect Dis 2008, 197:1585-1593.

10. Labadie $k$, Larcher T, Joubert C, Mannioui A, Delache B, Brochard P, Guigand L, Dubreil L, Lebon P, Verrier B, de Lamballerie X, Suhrbier A, Cherel $Y$, Le Grand R, Roques P: Chikungunya disease in nonhuman primates involves long-term viral persistence in macrophages. $J$ Clin Invest 2010, 3:894-906.

11. Jaffar-Bandjee MC, Das T, Hoarau JJ, Krejbich-Trotot P, Denizot M, Ribera A, Roques $P$, Gasque P: Chikungunya virus takes centre stage in virally induced arthritis: possible cellular and molecular mechanisms to pathogenesis. Microbes Infect 2009, 11:1206-18.

12. Hoarau JJ, Jaffar Bandjee MC, Krejbich Trotot P, Das T, Li-Pat-Yuen G, Dassa B, Denizot M, Guichard E, Ribera A, Henni T, Tallet F, Moiton MP, Gauzère BA, Bruniquet $S$, Jaffar Bandjee Z, Morbidelli P, Martigny G, Jolivet M, Gay F, Grandadam M, Tolou H, Vieillard V, Debré P, Autran B,
Gasque P: Persistent chronic inflammation and infection by chikungunya arthritogenic alphavirus in spite of a robust host immune response. J Immunol 2010, 184:5914-5927.

13. Economopoulou A, Dominguez M, Helynck B, Sissoko D, Wichmann O, Quenel P, Germonneau P, Quatresous I: Atypical Chikungunya virus infections: clinical manifestations, mortality and risk factors for severe disease during the 2005-2006 outbreak on Réunion. Epidemiol Infect 2008, 137:534-541.

14. Rajapakse S, Rodrigo C, Rajapakse A: Atypical manifestations of chikungunya infection. Trans R Soc Trop Med Hyg 2010, 104:89-96.

15. Couderc T, Chrétien F, Schilte C, Disson O, Brigitte M, Guivel-Benhassine F, Touret Y, Barau G, Cayet N, Schuffenecker I, Desprès P, ArenzanaSeisdedos F, Michault A, Albert ML, Lecuit M: A mouse model for Chikungunya: young age and inefficient type-l interferon signaling are risk factors for severe disease. PLOS Pathog 2008, 4:e29.

16. Gérardin P, Barau G, Michault A, Bintner M, Randrianaivo H, Choker G, Lenglet $Y$, Touret $Y$, Bouveret A, Grivard P, Le Roux K, Blanc S, Schuffenecker I, Couderc T, Arenzana-Seisdedos F, Lecuit M, Robillard PY: Multidisciplinary prospective study of mother-to-child chikungunya virus infections on the island of La Réunion. PLoS Me 2008, 5:e60.

17. Rampal, Sharda M, Meena H: Neurological complications in Chikungunya fever. J Assoc Physicians India 2007, 55:765-769.

18. Tournebize P, Charlin C, Lagrange M: Neurological manifestations in Chikungunya: about 23 cases collected in Réunion Island. Rev Neurol (Paris) 2009, 165:48-51.

19. Lemant J, Boisson V, Winer A, Thibault L, André H, Tixier F, Lemercier M, Antok E, Cresta MP, Grivard P, Besnard M, Rollot O, Favier F, Huerre M, Campinos JL, Michault A: Serious acute chikungunya virus infection requiring intensive care during the Réunion Island outbreak in 20052006. Crit Care Med 2008, 36:2536-2541.

20. Lalitha P, Rathinam S, Banushree K, Maheshkumar S, Vijayakumar R, Sathe P: Ocular involvement associated with an epidemic outbreak of chikungunya virus infection. Am J Ophthalmol 2007, 144:552-556.

21. Bhavana K, Tyagi I, Kapila RK: Chikungunya virus induced sudden sensorineural hearing loss. Int J Pediatr Otorhinolaryngol 2008, 72:257-259.

22. Inamadar AC, Palit A, Sampagavi W, Raghunath S, Deshmukh NS: Cutaneous manifestations of chikungunya fever: observations made during a recent outbreak in south India. Int I Dermatol 2008, 47:154-159.

23. Bandyopadhyay D, Ghosh SK: Mucocutaneous features of Chikungunya fever: a study from an outbreak in West Bengal, India. Int I Dermatol 2008, 47:1148-1152.

24. Chopra A, Anuradha V, Lagoo-Joshi V, Kunjir V, Salvi S, Saluja M: Chikungunya virus aches and pains: an emerging challenge. Ann Rheum Dis 2008, 58:2921-2922.

25. Bouquilllard $E_{1}$ Combe B: Rheumatoid arthritis after Chikungunya fever: a prospective follow-up study of 21 cases. Ann Rheum Dis 2009, 68:1505-1506.

26. Soumahoro MK, Gérardin P, Boëlle PY, Perrau J, Fianu A, Pouchot J, Malvy D, Flahault A, Favier F, Hanslik T: Impact of Chikungunya virus infection on health status and quality of life: a retrospective cohort study. PLoS One 2009, 14:e7800.

27. Gérardin P, Guernier V, Perrau J, Fianu A, Le Roux K, Grivard P, Michault A, de Lamballerie X, Flahault A, Favier F: Estimating Chikungunya prevalence in La Réunion Island outbreak by serosurveys: two methods for two critical times of the epidemic. BMC Infect Dis 2008, 8:99.

28. Gérardin P, Perrau J, Fianu A, Favier F: Determinants of Chikungunya virus in the Réunion Island: results of the Serochik seroprevalence survey, August - October 2006. Bull Epidemiol Hebd 2008, 38-3940:361-363.

29. Vazeille M, Moutailler S, Coudrier D, Rousseaux C, Khun H, Huerre M, Thiria J, Dehecq JS, Fontenille D, Schuffenecker I, Desprez P, Failloux AB: Two Chikungunya isolates from the outbreak of La Réunion (Indian Ocean) exhibit different patterns of infection in the mosquito Aedes albopictus. PLoS One 2007, 2:e1168.

30. Tsetsarkin KA, Vanlandingham DL, Mc Gee CE, Higgs S: A single mutation in chikungunya virus affects vector specificity and epidemic potential. PLoS Pathog 2007, 3:e201.

31. Salvan M, Mouchet J: Aedes albopictus et Aedes aegypti à l'île de La Réunion. Ann Soc Belge Med Trop 1994, 74:323-326. 
32. Paupy C, Delatte H, Bagny L, Corbel V, Fontenille D: Aedes albopictus, an arbovirus vector: from the darkness to the light. Microbes Infect 2009, 11:1177-1185

33. Urwin M, Symmons D, Allison $T$, Brammah $T$, Busby $H$, Roxby $M$, Simmons A, Williams G: Estimating the burden of musculoskeletal disorders in the community: the comparative prevalence of symptoms at different anatomical sites, and the relation to social deprivation. Ann Rheum Dis 1998, 57:649-655.

34. Vandenbroucke JP: When are observational studies as credible as randomised trials. Lancet 2004, 363:1728-1731.

35. Fourie ED, Morrison JG: Rheumatoid arthritic syndrome after Chikungunya fever. S Afr Med J 1979, 56:130-132.

36. Kennedy AC, Fleming J, Solomon L: Chikungunya viral arthropathy. J Rheumatol 1980, 7:231-236.

37. Brighton SW, Prozesky OW, de la Harpe AL: Chikungunya virus infection. A retrospective study of 107 cases. S Afr Med J 1983, 63:313-315.

38. Simon F, Parola $P$, Grandadam $M$, Fourcade $S$, Oliver $M$, Brouqui $P$, Hance $P$, Kraemer P, Ali Mohamed A, de Lamballerie X, Charrel R, Tolou H: Chikungunya infection: an emerging rheumatism among travelers returned from Indian Ocean islands. Report of 47 cases. Medicine (Baltimore) 2007, 86:123-137.34

39. Larrieu S, Pouderoux N, Pistone T, Filleul L, Receveur MC, Sissoko D, Ezzedine K, Malvy D: Factors associated with persistence of arthralgia among Chikungunya virus-infected travelers: report of 42 French cases. J Clin Virol 2010, 47:85-88.

40. Condon RJ, Rouse IL: Acute symptoms and sequelae of Ross River virus infection in SouthWestern Australia: a follow-up study. Clin Diagn Virol 1995, 3:273-284

41. Laine M, Luukkainen R, Jalava J, Ilonen J, Kuusisto P, Toivanen A: Prolonged arthritis associated with Sindbis-related (Pogosta) virus infection. Rheumatology (Oxford) 2000, 39:1272-1274.

42. Laine $M$, Luukkainen $R$, Toivanen $A$ : Sindbis viruses and other alphaviruses as cause of human arthritic disease. J Intern Med 2004, 256:457-471.

43. Harley D, Bossingham D, Purdie DM, Pandeya N, Sleigh AC: Ross River virus disease in tropical Queensland: evolution of rheumatic manifestations in an inception cohort followed for six months. Med J Aust 2002, 177:352-355

44. Mylonas AD, Brown AM, Carthew TL, McGrath B, Purdie DM, Pandeya N, Vecchio PC, Collins LG, Gardner ID, de Looze FJ, Reymond EJ, Suhrbier A: Natural history of Ross River virus-induced epidemic polyarthritis. Med $J$ Aust 2002, 177:356-360.

45. Lokireddy S, Vemula S, Vadde R: Connective tissue metabolisms in chikungunya patients. Virol J 2008, 5:31.

46. Rulli NE, Guglielmotti A, Mangano G, Rolph MS, Apicella C, Zaid A, Suhrbier A, Mahalingam S: Amelioration of alphavirus-induced arthritis and myositis in a mouse model by treatment with bindarit, an inhibitor of monocyte chemotactic proteins. Arthritis Rheum 2009, 60:2513-2523.

47. de Andrade DC, Jean S, Clavelou P, Dallel R, Bouhassira D: Chronic pain associated with the Chikungunya fever: long lasting burden of an acute illness. BMC Infect Dis 2010, 10:31.

48. Däntzer R, Keller KW: Twenty years of research on cytokine-induced sickness behavior. Brain Behav Immun 2007, 21:153-160.

49. Vollmer-Conna U, Fazou C, Cameron B, Li H, Brennan C, Luck L, Davenport T, Wakefield D, Hicikie I, Lloyd A: Production of proinflammatory cytokines correlates with the symptoms of acute sickness behaviour in humans. Psychol Med 2004, 34:1289-1297.

50. Hickie I, Davenport T, Wakefield D, Vollmer-Conna U, Cameron B, Vernon SD, Reeves WC, Lloyd A, Dubbo Infection Outcomes Study Group: Post-infective and chronic fatigue syndromes precipitated by viral and non-viral pathogens: prospective cohort study. BMJ 2006, 333:575.

51. Capuron L, Fornwalt FB, Knight BT, Harvey PD, Ninan PT, Miller AH: Does cytokine-induced depression differ from idiopathic major depression in medically healthy individuals? J Affect Disord 2009, 119:181-185.

52. Powers AM, Logue $\mathrm{CH}$ : Changing patterns of chikungunya virus: reemergence of a zoonotic arbovirus. J Gen Virol 2007, 88:2363-2377.

53. Setbon M, Raude J: The impact of social and behavioural factors on infectious epidemics: the case of chikungunya disease on Réunion Island. Population 2008, 63:555-584.

54. De Peuter S, Lemaigre V, Van Diest I, Van den Bergh O: Illness-specific catastrophic thinking and overperception in asthma. Health Psychol 2008, 27:93-99.

\section{Pre-publication history}

The pre-publication history for this paper can be accessed here: http://www.biomedcentral.com/1741-7015/9/5/prepub

doi:10.1186/1741-7015-9-5

Cite this article as: Gérardin et al:: Perceived morbidity and community burden after a Chikungunya outbreak: the TELECHIK survey, a population-based cohort study. BMC Medicine 2011 9:5.

\section{Submit your next manuscript to BioMed Central and take full advantage of:}

- Convenient online submission

- Thorough peer review

- No space constraints or color figure charges

- Immediate publication on acceptance

- Inclusion in PubMed, CAS, Scopus and Google Scholar

- Research which is freely available for redistribution

Submit your manuscript at www.biomedcentral.com/submit
Biomed Central 